\title{
ANÁliSE DE UMA AÇÃo COLETIVA: COMUNICAÇÃo E MOBILIZAÇÃO EM DEFESA DO DIREITO DE ESCOLHA DA MULHER EM RELAÇÃO AO PARTO
}

\author{
Aline Gonçalves \& Celsi Silvestrin
}

\begin{abstract}
Resumo
Neste artigo são apresentados alguns dos resultados da pesquisa Da Internet às Ruas: a Marcha do Parto em Casa. Com base na discussão a respeito do papel da comunicação e dos atores coletivos na sociedade, o trabalho teve por objetivo observar se as pessoas envolvidas na defesa da humanização do parto conseguiram, utilizando ferramentas disponíveis na internet e acionando a mídia, ampliar a visibilidade social do tema. Realizou-se uma análise documental, cujo corpus foi composto por peças de comunicação relacionadas ao conflito estabelecido entre as pessoas que defendem o parto humanizado e o Conselho Regional de Medicina do Rio de Janeiro (Cremerj). A análise de conteúdo de uma página de evento no Facebook, usada para a organização da Marcha, confirmou que o site teve papel central nesse processo, por isso a metodologia de estudo foi focada nas apropriações tanto da internet quanto das redes sociais. Para esclarecer dúvidas e confirmar ou refutar hipóteses, foram realizadas entrevistas em profundidade com algumas das articuladoras da ação coletiva. Verificou-se que as pessoas envolvidas na mobilização se uniram para defender uma causa — o direito de escolha da mulher em relação ao parto. Para isso, as ativistas realizaram ações de comunicação e mobilização, visando à sensibilização da sociedade para que essa exija o cumprimento dos direitos das gestantes e mudanças do modelo de assistência obstétrica no Brasil.
\end{abstract}

\section{PALAVRAS-ChAVE}

Comunicação; ação coletiva; mobilização; parto; Facebook

\section{INTRODUÇÃO}

No ano de 2012, a prática do parto domiciliar, como uma opção de escolha da mulher, ganhou visibilidade nos principais meios de comunicação de massa no Brasil. A partir da discussão sobre o papel da comunicação e dos atores coletivos na sociedade, este trabalho teve por objetivo observar se as pessoas envolvidas na defesa da humanização do parto conseguiram ampliar a discutibilidade e visibilidade social do tema, utilizando ferramentas disponíveis na internet e acionando a mídia. Visou-se também apresentar elementos que ajudem a compreender as razões que levam mulheres brasileiras a contestar o modelo de assistência obstétrica vigente, a ponto de se organizarem e saírem às ruas para protestar.

$\mathrm{Na}$ linguagem médica, o parto é visto como um evento fisiológico que depende de acompanhamento por especialistas e oferece riscos para a gestante e o bebê. As mulheres que defendem o parto em casa e a humanização do atendimento apontam que o modelo hospitalar vigente é centrado nas necessidades da equipe médica e não respeita o tempo e o processo psicofísico da mulher parturiente. Para elas, a falta de 
informações com evidências científicas e de suporte emocional, entre outros aspectos, desestimulam, quando não impedem, o parto vaginal. Desta forma, os grupos de muIheres mobilizadas na Marcha do Parto em Casa visaram resgatar, em alguns aspectos, o lugar cultural e social do parto na sociedade. Como argumenta Torniquist, há evidências que além de ser um ato fisiológico, o parto tem papéis culturais.

O parto e nascimento são eventos a um só tempo biológico, cultural e individual: mulheres dão à luz de formas diferenciadas, conforme o contexto histórico em que vivem, sua cultura particular e experiências pessoais incluindo-se as narrativas e lembranças guardadas na memória. Situando-se menos como uma doença - à exceção dos partos em que há graves dificuldades e mais como um fenômeno que envolve corpo e saúde, o parto é vivenciado como um ritual de passagem, que assinala mudanças tanto corporais, quanto familiares e sociais. (Torniquist, 2004, p. 65)

Ao considerar essas questões, pode-se entender a manifestação de centenas de mulheres brasileiras em defesa do direito de escolha e da autonomia da parturiente como um indicativo de mudança cultural e social. O grupo mobilizado afirma que a principal evidência de que está havendo o cerceamento da liberdade da mulher é o crescente número de cesarianas que vem sendo realizadas, principalmente na rede privada de atendimento à saúde. Em 2010, segundo dados do Ministério da Saúde - Governo do Brasil, o país foi considerado líder mundial na proporção de nascimentos via cesariana. Naquele ano, registrou-se que $52 \%$ dos nascimentos aconteceram por via cirúrgica. $\mathrm{Na}$ rede privada, o índice de cesáreas foi de $82 \%$, e na rede pública, de $37 \%$. A recomendação da Organização Mundial da Saúde (OMS) é que a taxa esteja em torno de 15\%.

Há experiências pontuais em algumas maternidades públicas, como a do Hospital Sofia Feldman, em Belo Horizonte (MG), que prestam assistência humanizada, mas, apesar dos indicativos de investimento do Governo Federal, segundo as ativistas não há indicativos de que essas práticas possam se tornar acessíveis de maneira universal. Diante desse cenário, algumas mulheres brasileiras optam por ter seus filhos em casa, mesmo quando vivem em regiões urbanas e têm acesso às redes pública e privada de assistência médica. Na opinião de Ana Cristina Duarte, obstetriz, uma das fundadoras do Grupo de Apoio à Maternidade Ativa (GAMA) e uma das principais articuladoras da Marcha do Parto em Casa, “(...) o melhor lugar para se ter o bebê é onde a mulher se sente mais segura. Se ela se sente mais segura na casa dela, precisa procurar opções para ter o bebê em casa" (IHU Unisinos, 2012). Ponto de vista oposto ao do Conselho de Medicina do Rio de Janeiro, cujos representantes consideram o parto em casa um procedimento de risco. Apesar de o parto domiciliar não ser assistido pelas redes pública ou privada de saúde, tampouco existe qualquer restrição legal para a prática, tornando-se um tema complexo e polêmico, no qual precisam ser analisados aspectos do âmbito da saúde, da cultura e da sociedade. 


\section{O PAPEL DA COMUNiCAÇÃo E doS ATORES COletivos}

A Marcha do Parto em Casa teve características comuns com manifestações desencadeadas após o ano 2000, nas quais os atores acionaram, entre outros, recursos tecnológicos como a internet e a telefones móveis. Grandes e expressivas mobilizações como a Revolução de Jasmim, na Tunísia (2010) e a Revolução Egípcia (2011) são alguns dos exemplos de mobilização social, nas quais as tecnologias da informação e comunicação fizeram com que fosse possível aos cidadãos transmitir, compartilhar ou trocar informações de interesse comum. Segundo Shirky (2012), a rede de computadores permite o contato entre pessoas que têm um mesmo propósito, sem que seja necessário um alto investimento. Assim, para o autor, ações que seriam inviáveis economicamente em um padrão organizacional tradicional, podem ser desenvolvidas com o aporte das ferramentas sociais (2012, p. 44). Para Pleyers (2009), que estuda movimentos sociais recentes como o zapatismo,

[...] não se trata tanto de um declínio ou lacunas de movimentos imaturos, mas uma mutação das formas de participação e atores sociais que: adotam uma concepção de mudança social que é centrada na sociedade, nas pessoas e nas organizações locais, mais que em decisões dos representantes políticos ou de instituições internacionais. (Pleyers, 2009, p. 126)

Como afirma Pleyers, na contemporaneidade, a pulverização e diversificação das ações coletivas apresentam desafios teóricos e metodológicos que vão além daqueles debatidos em torno da participação política e das formas já conhecidas de organizações da sociedade civil, como os partidos ou os movimentos sociais (Luke et al., 2013), fazendo com que as discussões teóricas sofram aportes constantemente. A Marcha do Parto em Casa foi organizada por meio das redes sociais virtuais e realizada nos dias 16 e 17 de junho de 2012, em 30 cidades brasileiras. Para estudá-la optou-se por uma abordagem metodológica de natureza qualitativa, com a finalidade de explorar, por meio de um estudo de caso, duas questões consideradas centrais: comunicação e mobilização. Assim, os conceitos relacionados à ação coletiva, redes e meios de comunicação contextualizam o objeto investigado, tendo como finalidade identificar como se deu a organização dos indivíduos na ação analisada, tornando-os capazes de agir conjuntamente. O corpus desta pesquisa foi composto por textos provenientes de reportagens sobre a manifestação, utilizando a técnica de análise documental; entrevistas com nove ativistas envolvidas na organização da Marcha - que foram eleitas por terem sido os nomes de referência para conceder entrevistas à imprensa sobre a Marcha nos seus respectivos estados; e registros feitos pelo grupo mobilizado no site de rede social Facebook. Embora todo o material coletado tenha sido utilizado para situar o objeto de estudo, a análise de conteúdo (Bardin, 2011) restringiu-se à página do evento Marcha do Parto em Casa, no Facebook, por ter sido apontado pelas envolvidas como a principal ferramenta de mobilização na ação coletiva.

Neste trabalho, a Marcha do Parto em Casa foi considerada uma ação coletiva, a partir dos apontamentos de Melucci, que entende o conflito, a solidariedade e o 
rompimento dos limites do sistema como dimensões analíticas básicas para o estudo dessas ações (Melucci, 1980, 1982 e 1983):

Defino conflito como uma relação entre atores opostos, lutando pelos mesmos recursos aos quais ambos dão um valor. A solidariedade é a capacidade de os atores partilharem uma identidade coletiva (isto é, a capacidade de reconhecer e ser reconhecido como uma parte da mesma unidade social). Os limites de um sistema indicam o espectro de variações tolerado dentro de sua estrutura existente. Um rompimento destes limites empurra um sistema para além do espectro aceitável de variações. (Melucci, 1989, p. 56)

No caso analisado, o dissenso ocorreu entre os grupos que defendem o parto humanizado - e menos institucionalizado e medicalizado - e o Conselho de Medicina do Estado do Rio de Janeiro (Cremerj) que saiu em defesa das práticas da corporação. A formação do ator coletivo, ou da identidade coletiva, foi observada na capacidade que as pessoas envolvidas tiveram para dar sentido às suas ações. Nessa perspectiva, os atores sociais seriam definidos, ao mesmo tempo, por assumirem uma causa que gera conflito (contra o que está estabelecido, é hegemônico) e por uma vontade de origem subjetiva de participação. Esse conjunto de características pode levar ao que Melucci chama de identidade coletiva: "A identidade coletiva é uma definição interativa e compartiIhada produzida por numerosos indivíduos e relativa às orientações da ação e ao campo de oportunidades e constrangimentos no qual a ação acontece (1988, p. 342).

Assim, a identidade coletiva é acionada pela ação dos atores diante de uma oportunidade, ou seja, ela pode estar latente em uma rede e emergir em momento de conflito. Como explica Gamson (2011, pp. 28-29), "A ação coletiva requer a consciência de agentes humanos cujas políticas e práticas precisam ser mudadas e é a consciência de um "nós" que irá ajudar a realizar essa mudança". Para Melucci, o componente da identidade refere-se ao processo de definição desse "nós", tipicamente em oposição a um "eles" que possui interesses ou valores diferentes. A rede construída pelos que defendem a humanização do parto foi tecida por diversos anos, inicialmente por encontros presenciais, e somente nos período mais recente com o aporte blogs e outras ferramentas de interação via internet (listas de discussão, sites de redes sociais).

\section{O PROCESSO DE MOBILIZAÇÃo}

O processo analisado aqui tem como marco inicial a publicação do vídeo Parto de Sabrina - Nascimento de Lucas, em 21 de fevereiro de 2012, no site Youtube. Antes mesmo de ter sido pauta em sites jornalísticos ou programas de grande audiência na TV, o vídeo teve mais de dois milhões de visualizações', que, segundo suas realizadoras, podem ser atribuídas a sua divulgação nas redes sociais e em blogs relacionados ao assunto.

'Em janeiro de 2014, um ano e 11 meses após a sua publicação, o vídeo contava com 7310775 - continuando a ser um dos vídeos de parto mais vistos no Youtube. 
No dia 10 de junho de 2012, o vídeo foi tema de reportagem no programa Fantástico, revista semanal da Rede Globo de Televisão, um dos programas jornalísticos de maior audiência da televisão brasileira. A reportagem Parto Humanizado Domiciliar causa polêmica entre profissionais da saúde e teve quase cinco minutos de duração, o que pode ser considerado um tempo longo para uma matéria de telejornalismo. Nela o repórter enfatiza que o parto em casa gera divergência entre profissionais e afirma que o Conselho Nacional de Enfermagem aprova a prática, com ressalvas, mas que o Conselho Federal de Medicina, a Federação Brasileira de Ginecologia e Obstetrícia e o Ministério da Saúde desaprovam. A fala do médico obstetra Jorge Kuhn que causou a reação dos conselhos de medicina foi a seguinte:

[Repórter (em off): o coordenador do departamento de obstetrícia da Universidade Federal de São Paulo defende o parto em casa, mas avisa que o parto só pode ser feito quando a gravidez é de baixíssimo risco.]

Jorge Kuhn: aquelas que não apresentam nenhuma intercorrência, quer clínica, quer obstétrica, portanto pressão alta, diabetes, pré-eclampsia, qualquer circunstância que possa aumentar o risco para essa mãe ou esse bebê.

No dia posterior, 11 de junho, uma matéria no site do Jornal do Brasil relatava que o Cremerj divulgou nota para a imprensa com o seguinte posicionamento em relação à declaração de Jorge Kuhn exibida no Fantástico.

O Conselho Regional de Medicina do Estado do Rio de Janeiro (Cremerj) enviará denúncia ao Conselho Regional de Medicina do Estado de São Paulo contra o médico Jorge Francisco Kuhn, que participou de reportagem do Fantástico defendendo o parto domiciliar³.

A reportagem exibida na Rede Globo foi bastante comentada e elogiada na rede social Facebook pelas mulheres que defendem o parto humanizado. Porém, o entusiasmo de ter conseguido levar o assunto a milhões de brasileiros em horário nobre logo foi substituído pelo sentimento de indignação diante da atitude tomada pelo Cremerj.

Movida por esse sentimento, na noite de segunda-feira (11/06/2012), a bióloga e doula Gisele Leal, de Sorocaba (SP), criou no Facebook a página do evento Marcha do Parto em Casa, por meio da qual as ativistas organizaram a manifestação. Em quatro dias foram mobilizadas pessoas em 30 cidades, de 17 estados, em todas as regiões do Brasil. A página do evento registra que 9.322 pessoas foram convidadas, e, destas, 1.964 confirmaram presença. Além dessa página de abrangência nacional, foram criadas no Facebook páginas de eventos locais e de grupos de organização em que as internautas organizaram a Marcha em suas cidades. Paralelamente a isso, surgiram dezenas de

\footnotetext{
${ }^{2}$ Acedido em http://globotv.globo.com/rede-globo/fantastico/v/parto-humanizado-domiciliar-causa-polemica-entre-profissionais-da-area-de-saude/1986583/.

3 Acedido em http://www.jb.com.br/rio/noticias/2012/06/11/cremerj-abrira-denuncia-contra-medico-que-defende-parto-domiciliar.
} 
instituições, associações e empresas que manifestaram publicamente apoio ao parto domiciliar, porém, com exceção do Conselho Regional de Enfermagem do Rio de Janeiro (Coren-RJ) e das instituições de ensino, as demais são ligadas diretamente a profissionais que prestam serviços humanizados ao parto. As passeatas de rua ocorreram nos dias 16 e 17 de junho; os organizadores estimam que, somente em São Paulo, 1.500 pessoas compareceram. Houve cidades em que a manifestação contou com menos de dez pessoas, outras com algumas dezenas. São Paulo, Rio de Janeiro e Brasília foram as capitais que tiveram um número mais expressivo de participantes. No quadro a seguir são listadas as cidades em que ocorreu a Marcha.

\begin{tabular}{|c|c|c|}
\hline REGIÃO & ESTADO & CIDADES \\
\hline \multirow{3}{*}{ SUL } & Paraná & Curitiba, Cascavel, Londrina \\
\hline & Santa Catarina & Florianópolis, Garopaba \\
\hline & Rio Grande do Sul & Porto Alegre \\
\hline \multirow{4}{*}{ SUdESTE } & São Paulo & $\begin{array}{l}\text { São Paulo, Bauru, Campinas, Ilha Bela, Ribeirão } \\
\text { Preto, São Carlos, São José dos Campos, Sorocaba }\end{array}$ \\
\hline & Rio de Janeiro & Rio de Janeiro \\
\hline & Espírito Santo & Vitória \\
\hline & Minas Gerais & Belo Horizonte, Uberlândia \\
\hline \multirow{2}{*}{ Centro-Oeste } & Distrito Federal & Brasília \\
\hline & Goiás & Goiânia \\
\hline \multirow{6}{*}{ NORDESTE } & Bahia & Salvador, Capão \\
\hline & Ceará & Fortaleza \\
\hline & Paraíba & Campina Grande \\
\hline & Maceió & Maceió \\
\hline & Rio Grande do Norte & Natal \\
\hline & Pernambuco & Recife \\
\hline \multirow{2}{*}{ NORTE } & Pará & Belém \\
\hline & Rondônia & Porto Velho, Cacoal \\
\hline
\end{tabular}

As imagens das manifestações nas ruas das cidades em que houve maior aglomeração de pessoas (centenas ou dezenas) eram de mulheres com filhos, gestantes (muitas de barrigas expostas e pintadas) e alguns homens que carregavam cartazes, faixas e megafones. Entre as frases mais presentes durante a manifestação estiveram: "Não preciso de Conselho para parir", "Meu parto, minhas escolhas", "Eu decido", "Deixe eu dar à luz no meu canto", "I love Jorge Kuhn" e "Meu corpo, meu parto, minhas escolhas". Várias crianças usavam camisetas em que se lia: "Eu nasci em Casa". No Rio de Janeiro, os manifestantes foram até a frente do Cremerj e em São Paulo até a frente do Cremesp, como um ato simbólico de comunicar a sua indignação. 
No domingo (17/06/12), o Fantástico veiculou uma nova reportagem, com o título Mulheres fazem manifestação a favor do parto em casa4, com duração de três minutos e meio. Nela são mostradas imagens das manifestações em algumas cidades brasileiras, como Curitiba, Salvador e São Paulo - o repórter relata que a manifestação ocorreu em 12 cidades5. Nessa reportagem do Fantástico, o médico Jorge Kuhn é novamente entrevistado e o posicionamento do Conselho Regional de Medicina do Rio de Janeiro é expresso pelo médico obstetra Luis Fernando Moraes. A seguir, as transcrições das falas dos médicos na reportagem.

Luis Fernando Moraes: "Nós entendemos que as afirmações que ele fez na matéria do Fantástico não são éticas".

Jorge Kuhn: "Eu já imaginava que isso pudesse acontecer, eu apenas acho que há um certo exagero, porque se a gente for ver as evidências científicas em relação a esse assunto a mortalidade é a mesma".

A manifestação e o conflito entre Cremerj e Jorge Kunh tiveram grande repercussão em outros veículos midiáticos, tanto de abrangência nacional quanto local. Após as manifestações e a ampla repercussão do debate na mídia, no dia 18 de junho, o Cremerj publicou em seu site a denúncia contra Jorge Kuhn. A posição do Cremerj não diverge da do Conselho de Medicina de São Paulo (Cremesp) que já havia proibido os profissionais de trabalharem nas casas de parto, tendo, inclusive, o assunto sido colocado em discussão no site do órgão há alguns anos: os médicos já haviam sido impedidos formalmente por esse conselho de prestar assistência em casas de parto e em domicílios.

Após o dia 18 de junho, alguns órgãos representativos de classes, na área da saúde, como o Coren-RJ, lançaram manifestos em apoio ao parto domiciliar e em repúdio à atitude do Cremerj.

No dia 17 de julho, o Conselho de Medicina vetou a participação de obstetrizes, parteiras e doulas (acompanhantes de gestantes) na assistência e no acompanhamento de mulheres grávidas antes, durante e após o parto no hospital. Diante dessa nova resolução, em 27 de julho, o Coren-RJ entrou com uma ação civil pública na Justiça Federal contra as resoluções do Cremerj e obteve parecer favorável (suspendendo as resoluções do Conselho de Medicina) no dia 30 do mesmo mês. O juiz deferiu a favor do Coren. Diante desse processo, a rede mobilizada em defesa do parto domiciliar organizou uma nova manifestação em âmbito nacional, que foi agendada para o dia 05 de agosto. Desta vez, as ativistas usaram a experiência passada para aprimorar a organização do ato, assim como articular de forma mais consistente argumentos científicos e políticos.

Como já ressaltado, o uso das redes sociais foi primordial nesse processo, porém, sem a visibilidade proporcionada pela televisão e o efeito de milhares de pessoas saindo

\footnotetext{
4 Acedido em http://globotv.globo.com/rede-globo/fantastico/v/mulheres-fazem-manifestacao-a-favor-do-parto-em-casa/1997988/.

5 Os organizadores da Marcha editaram posteriormente vídeo no qual, por meio de fotos e vídeos, registraram a Marcha em 30 cidades brasileiras. Acedido em https://www.youtube.com/watch?v=Kt-bTOnRSwE.
} 
às ruas de forma sincronizada, em 30 cidades, a discussão em torno do parto provavelmente não teria tido a mesma proporção. As pessoas ligadas à defesa do parto em casa demonstravam familiaridade com as redes sociais e com o uso de blogs, o que facilitou a disseminação por meio do mundo virtual. Além disso, alguns de seus integrantes estavam atentos à necessidade de tornar o posicionamento público utilizando a mídia de massa. A necessidade de sair das redes virtuais e ir a público, por meio dos meios de comunicação de massa, é justificada pelo poder de disseminação de informações que a TV ainda detém. Segundo Wolton (2011), a televisão serve para se ter o que falar: "A televisão é um formidável instrumento de comunicação entre indivíduos. O mais importante não é o que é visto, mas o fato de se ter o que falar" (Wolton, 2011, p. 69). Para o autor, o problema essencial da televisão é conservar a tensão entre duas dimensões contraditórias, mas que também são a razão do seu sucesso: a de consumo individual e a de uma atividade coletiva. Não se propõe, com isso, que a televisão determina o que as pessoas vão pensar, ou como vão formar suas opiniões, e sim que esta pode influenciar o que as pessoas vão pensar e falar, como aponta a teoria agenda-setting, desenvolvida por Donald Shaw e Maxwell McCombs (1972). "Agenda-setting se refere à ideia de que há uma forte correlação entre a ênfase dada pela mídia em certos temas e a importância atribuída para esses temas pelas audiências" (Scheufele \& Tewksbury, 2007, p. 9). As pesquisas empíricas com base nesse referencial teórico apontaram que também ocorre o que é chamado de contra-agendamento:

O pressuposto da contra-agenda é o de que a sociedade não necessita majoritariamente da mídia para se informar a respeito de tudo o que ocorre ao seu redor. Ela consegue encontrar informações em outras fontes, em ambientes informacionais externos à mídia tradicional. Mas uma dimensão ganha destaque: as relações interpessoais [...]. É no seio do debate público, destas relações interpessoais, que surge uma força capaz de influenciar a mídia (Cervi \& Barreta, 2014, p. 138).

Assim, uma dinâmica simbiótica formada por redes de pessoas, sites de redes sociais e a mídia colocou em discussão o tema parto. O debate gerado entre as mulheres na rede social Facebook e a realização da Marcha do Parto em Casa foi capaz de agendar a mídia mais de uma vez. Em um primeiro momento, com o vídeo do parto de Sabrina e sua repercussão, e no segundo momento, com a realização da Marcha. A ampliação do conflito levou à discussão para além da esfera midiática e refletiu em instâncias jurídicas (Conselho Nacional de Justiça, Ministério Público) e políticas (Congresso Nacional, Câmara de Deputados do Estado de São Paulo). Diante disso, pode-se dizer que os defensores do parto domiciliar conseguiram agendar os meios de comunicação, obtendo, em algum grau, o resultado almejado. 


\section{A INTERNET COMO FERRAMENTA DE ARTICULAÇÃo}

O conteúdo da página do evento Marcha do Parto em Casa ${ }^{6}$ evidencia parte do processo de organização da manifestação. Na página do evento foi possível encontrar vários registros diários de como a mobilização ocorreu. Essa página pode ser considerada um grande mural público de informações a respeito da ação coletiva, construído, principalmente, por pessoas que estão vinculadas diretamente à defesa da causa. Nela foram publicadas postagens (posts) e também comentários relacionados a essas postagens. Assim, ficaram registradas as trocas de informações, as discussões e as interações entre as organizadoras da Marcha e também delas com outras pessoas que são vinculadas diretamente à humanização do parto. Um espelho dessa página do Facebook resultou em um documento digital com 331 páginas (em formato PDF), cujo conteúdo foi analisado.

Para essa análise de conteúdo foram seguidos os passos apontados por Bardin (2011): pré-análise, exploração dos resultados e interpretação. Na primeira etapa, após uma leitura flutuante de todo o material, foram criadas as categorias e as subcategorias, com base na teoria adotada. Na sequência foram selecionados excertos de conversações representativos em cada subcategoria, cujos dados foram interpretados. Os indicadores para seleção de conteúdos para análise usados foram a presença (ou ausência) de expressões ou ideias relacionadas às categorias eleitas. Foram utilizadas as seguintes categorias e subcategorias:

\begin{tabular}{|c|c|}
\hline CATEGoRIAS & SUBCATEGORIAS \\
\hline 1. COMUNICAÇÃO & $\begin{array}{l}\text { 1.1 Mídias } \\
1.2 \text { Interação } \\
1.3 \text { Netativismo }^{8}\end{array}$ \\
\hline 2. IDENTIDADE & $\begin{array}{l}\text { 2.1 Identidade coletiva: mulher, mãe, ativista } \\
\text { 2.2 Feminismos } \\
\text { 2.3 Articuladoras }\end{array}$ \\
\hline 3. AçÃo & $\begin{array}{l}\text { 3.1 Organização } \\
3.2 \text { Mobilização } \\
3.3 \text { Oportunidade }\end{array}$ \\
\hline 4. INJUSTIÇA & $\begin{array}{l}\text { 4.1 Oponentes } \\
\text { 4.2 Danos e sofrimento }\end{array}$ \\
\hline
\end{tabular}

\footnotetext{
${ }^{6}$ A bióloga e doula Gisele Leal foi quem teve a iniciativa de organizar o evento a Marcha do Parto em Casa, utilizando o recurso para esse fim disponível no Facebook, a principal ferramenta usada pelas manifestantes para organizar e mobilizar nacionalmente as pessoas a participarem do ato. A ferramenta 'eventos' da rede social Facebook tem o potencial de gerar um efeito viral na internet: isso ocorre quando uma mesma mensagem é vista e compartilhada por milhares, ou milhões de internautas, em um mesmo período de tempo. Na página de um evento, como a da Marcha do Parto em Casa, os organizadores conseguem fazer convites a todos os seus amigos na rede. As pessoas que foram convidadas também podem estender o chamado para outros amigos, aumentando o número de convidados exponencialmente. Esses convites em cadeia podem fazer com que a mensagem de divulgação do evento apareça com frequência nas timelines de pessoas interligadas pela rede (devido ao algoritmo aplicado no sistema de gerenciamento do Facebook).
}

7 A descrição completa das categorias pode ser encontrada em Gonçalves, 2014.

${ }^{8}$ Ao propor uma abordagem que visa analisar de forma integrada as ações 'em rede' e 'na rede mundial de computadores', Felice utiliza o conceito netativismo, "de forma a não restringir o seu significado ao âmbito da democracia eletrônica e das redes cidadãs de participação política" (2012, p. 36). O autor ressalta que características das ações coletivas na contemporaneidade como autonomia, criatividade, identidade local-global (glocal) trazem novos elementos que precisam ser observados de forma tencionada à apropriação das tecnologias. Para ele, "A forma de cidadania e ativismo que caracteriza tais movimentos é resultado de uma interação fecunda entre sujeitos, grupos e entidades com as tecnologias de informação, as redes informativas e as diversas interfaces utilizadas (Felice, 2012, p. 36). 


\section{RESULTADOS DAS ANÁLISES}

Com este estudo, pode-se constatar que a ação coletiva apresentou as três perspectivas analíticas apontadas por Melucci: (1) conflito - com o Cremerj; (2) solidariedade - a identificação das envolvidas com a causa e a motivação de sensibilizar e informar mais pessoas a respeito da problemática relacionada ao parto; (3) rompimento com os limites do sistema - ao incentivarem a prática do parto em casa, cuja assistência não é possível, nem estimulada pelos sistemas de saúde público e privado. Também atendeu ao que Gamson define como enquadramentos da ação coletiva: identidade, formação de uma ideia de nós; ação, "observação de sentido na ação coletiva e negação da imutabilidade de alguma situação indesejável"; e injustiça, "indignação moral expressa em forma de consciência política e está ligada a expressões ligadas às emoções" (Maia citado em Gamson, 2011, p. 19).

Com a análise dos posts da página do evento no Facebook categorizados como expressões de identidade, pôde-se considerar que a identidade coletiva foi expressa no momento em que o Conselho Regional de Medicina do Rio de Janeiro (Cremerj) se posicionou de forma contrária daqueles que defendem o direito que a mulher tem de escolher o lugar em que irá parir. Nesse "nós" podem ser incluídos os indivíduos que defendem esse ponto de vista. Assim, momentaneamente, foi possível verificar a formação de uma identidade coletiva solidária, sendo indicadores dessa unicidade: a abrangência numérica e territorial da manifestação, que reuniu pessoas em 30 cidades em todas as regiões do país; a sincronia, uma vez que todas as manifestações de rua ocorreram nos dias 16 e 17 de junho; e a uniformidade de linguagem usada em faixas, cartazes e falas durante as manifestações e nas entrevistas para a imprensa.

Ainda em relação à identidade, entre as entrevistadas para esta pesquisa, foi possível aferir que é recorrente a experiência de terem passado por uma cesariana que, posteriormente, consideraram desnecessária. Esse fato as motivou a buscarem informações, pela internet, ou a integrarem grupos que defendam o parto humanizado. Outras características frequentes entre as mulheres mobilizadas: acesso à assistência médica privada (planos e saúde ou atendimento particular); usuária frequente de internet; escolaridade de nível superior; prestadora de serviços para gestantes e parturientes (doulas, 9 fotógrafas, obstetrizes); não envolvimento com a política partidária — algumas das entrevistadas afirmaram que a sua forma de fazer política é defender a sua causa: o parto humanizado, ou seja, a maior parte das entrevistadas não manifestou participar, naquele momento, de outras mobilizações sociais, associações ou partidos políticos, além de estar envolvida, como mobilizadora na Marcha.

Nos registros das manifestações feitos pela imprensa, pôde ser observado que muitas das mulheres que foram às ruas estavam grávidas - a presença de crianças

\footnotetext{
${ }_{9}^{9}$ A palavra doula, em grego, significa aquela que serve outra mulher, e refere-se à acompanhante de parto especialmente treinada para oferecer apoio contínuo físico e emocional à parturiente e a seu parceiro durante o trabalho de parto e o parto, trazendo-lhes segurança e tranquilidade. A doula não substitui o acompanhante escolhido pela parturiente e muito menos o obstetra. Em seu trabalho, ela utiliza técnicas de respiração, relaxamento, massagem e métodos não-farmacológicos de alívio à dor, e auxilia a mulher na escolha de posições mais confortáveis para o parto. Vários estudos científicos mostram os resultados deste apoio contínuo, entre eles, reduzir o número de cesarianas, a duração do trabalho de parto e o uso de analgesia. Acedido em http://www.institutoaurora.com.br/produtos/livro_doula.
} 
também foi expressiva, mas havia poucos homens. Sob o ponto de vista de Touraine (2007, p. 65), não seria estranha a participação expressiva de gestantes na manifestação, uma vez que o sociólogo considera que as mulheres alcançam sua força máxima durante a gravidez. Essa foi uma das suas constatações com base em uma série de entrevistas, por meio das quais buscou compreender o pensamento e a experiência vivida pelas mulheres contemporâneas, na França. Em relação à participação de homens, tanto nas ruas quanto na página do Facebook, poucos se manifestaram: alguns dos homens que defendem o parto nas redes sociais são médicos que seguem a abordagem humanizada e um único homem foi citado como fonte para a imprensa durante a organização da Marcha: Diego Vieira de Mattos, enfermeiro obstétrico, que reside em Goiânia (GO).

Quanto à organização da ação, durante as entrevistas realizadas para a pesquisa, foi recorrente a afirmação de que a Marcha foi uma iniciativa de pessoas, que não havia líderes ou representantes. Essas características correspondem ao que Shirky (2012) define como alternativa à ação institucional ou a nenhuma ação: "ferramentas sociais fornecem uma terceira alternativa: ação por grupos de estrutura frouxa, operando sem direção gerencial e sem o motivo do lucro" (Shirky, 2012, p. 44). Ana Cristina Duarte, em entrevista concedida para esse trabalho, se posicionou da seguinte forma:

Todas as pessoas que estão ali no meu Facebook, que é usado exclusivamente para trabalho, todas as pessoas que estão ali são ativistas. E todas elas estão mobilizadas por essa causa. Mas o que faz gerar uma passeata é a gente ter uma questão específica e alguém pisando na bola (...). Isso foi feito de um jeito horroroso e caiu nas graças das ativitas. Então precisa ter uma causa específica, precisa ter um inimigo específico que o enxameamento vai acontecer sozinho. (Duarte, 2013)

A identificação ou a representatividade por instituições não foi observada diretamente. As organizações e as empresas a que algumas das manifestantes são ligadas aparecem apenas em uma lista de Apoiadores da Marcha, ou seja, as organizações ficaram em um papel secundário. A instituição mais antiga, e talvez mais abrangente, em defesa do parto humanizado - a Rede Nacional pela Humanização do Nascimento (Rehuna) foi citada algumas vezes durante o processo de mobilização, mas seus representantes não apareceram como articuladores da Marcha.

No conteúdo da página do evento, assim como nas entrevistas realizadas, foi possível confirmar que o uso do site Facebook permitiu às pessoas envolvidas com a causa a comunicação instantânea e a ação de forma articulada em defesa de interesses comuns. Além disso, foi possível identificar que integrantes do grupo possuíam um repertório argumentativo coeso; relacionamentos com pessoas que atuam em veículos de comunicação; e recursos financeiros disponibilizados voluntariamente que viabilizaram a manifestação. Desde o ano de 2011, o Facebook, pelo seu recurso Eventos, é utilizado para divulgar manifestações de rua no Brasil. Algumas das organizadoras da Marcha do Parto em Casa temiam que o entusiasmo demonstrado no site não fosse reproduzido nas ruas. Isso porque muitos dos eventos propostos na plataforma do Facebook não passam de 
tentativas de manifestações de rua que reuniram poucos manifestantes no local, dias e horário agendados, mesmo que as confirmações de participação na rede social tenham sido expressivas - o que pode colocar em dúvida a eficiência dessa forma de ação ou organização. Mas na Marcha do Parto em Casa, nas cidades de São Paulo e Rio de Janeiro, o número de participantes foi expressivo e próximo ao confirmado na página do evento.

A linguagem que foi utilizada no Facebook é muito próxima de uma conversação oral informal em grupo: espontânea, direta, descontínua e, algumas vezes, repetitiva. As conversações mais intensas aconteceram entre o dia da criação da página (11 de junho) e os da sua realização (16 e 17 de junho). Como espaço de conversação e diálogo, pode-se considerar que a página do evento, predominantemente, canalizou expressões de pessoas que já tinham algum vínculo com a causa. A maior parte dos diálogos teve caráter prático, visando à organização do protesto, apenas algumas discussões conceituais atraíram um número significativo de participações, como, por exemplo, a discussão sobre o nome da Marcha.

Observou-se que nessa página não foi construído o diálogo com pessoas que explicitaram posições divergentes em relação às do grupo. As poucas manifestações distintas ao posicionamento predominante que apareceram na página do evento foram desqualificadas ou desconsideradas pelas internautas. Com isso, o grupo que preconiza o parto humanizado distingue pessoas que têm o mesmo ponto de vista em relação à assistência ao parto (defendem a assistência humanizada) daquelas que defendem práticas diferentes (medicalização, cesarianas eletivas). Esse posicionamento cria uma polaridade (dois grupos: "nós" e "eles") e dificulta o diálogo. Isso não exclui a possibilidade de terem ocorrido trocas de experiências e de conhecimentos entre pessoas com posicionamentos diferentes em outros espaços: ruas, programas de rádio e TV, ou mesmo em outros grupos de discussão na internet, cujos conteúdos não foram analisados nesta pesquisa.

Também foi possível constatar que, apesar de este não ser o foco principal da página do evento e da troca de informações, havia pessoas atentas a aspectos da conjuntura política e que usaram a página do evento para apontar outras oportunidades de ação. São exemplos: a reunião de relatos de casos de violência obstétrica para fazer denúncias ao Ministério Público; a sugestão de participação em audiências públicas do Ministério da Saúde; a sugestão de articulação com categorias de servidores públicos em greve; além da articulação com pessoas que militam por questões ambientais que estavam reunidas na Conferência Internacional $\mathrm{Rio}+2 \mathrm{O}^{\circ}$. O conjunto desses fatores relacionados à organização, mobilização e oportunidade tornou possível essa ação coletiva e sua repercussão nos meios de comunicação, fazendo com que alguns dos objetivos do grupo mobilizado fossem alcançados.

Pelo viés da comunicação, o estudo foi capaz de elucidar como a apropriação de recursos midiáticos (conhecimentos, técnicas e aparatos), contribuiu para a realização de

\footnotetext{
${ }^{10}$ A Conferência das Nações Unidas sobre Desenvolvimento Sustentável, a Rio+20, foi realizada de 13 a 22 de junho de 2012, na cidade do Rio de Janeiro. A Rio+20 foi assim conhecida porque marcou os vinte anos de realização da Conferência das Nações Unidas sobre Meio Ambiente e Desenvolvimento (Rio-92) e contribuiu para definir a agenda do desenvolvimento sustentável para as próximas décadas.
} 
uma ação coletiva, correspondendo ao que Wolton (2004) aponta como o papel central da comunicação na sociedade contemporânea. A pesquisa apontou que a comunicação teve papel central; ações de comunicação contribuíram para ampliar as discussões e a visibilidade social do tema; e que a mobilização coletiva e voluntária pode ser considerada uma forma de exercício político, dentro de uma visão ampliada de política. Considerando os meios de comunicação como agentes que integram as dinâmicas sociais (Silverstone, 2002), a visibilidade que a mídia deu ao tema parto pode ter deflagrado uma mudança de cenário, uma oportunidade para que a ação coletiva fosse impulsionada. Essa oportunidade foi constatada pelas articuladoras da Marcha, como relatado nas entrevistas, e pôde se tornar midiaticamente "um conduto para a representação do pensamento e da ação públicos e privados como o estimulante dela" (Silverstone, 2002, p. 266).

Segundo as entrevistadas para esta pesquisa, e também de acordo com as análises feitas da página do evento no Facebook, o processo de elaboração e distribuição dos materiais de comunicação ocorreu de forma colaborativa, em um processo interativo, no qual a espontaneidade e a disponibilidade prevaleceram. Foi observado que, entre as mulheres mobilizadas, havia algumas profissionais da área da comunicação, o que proporcionou a adequação da linguagem das ativistas ao enquadramento da mídia de massa, o que pode ter contribuído significativamente para ampliar a visibilidade da Marcha. O levantamento documental ajudou a evidenciar que algumas mulheres tinham familiaridade com recursos da internet que permitem ações aqui denominadas de netativismo (Felici, 2012). Elas utilizaram recursos como: twitaço, blogagem coletiva e petição virtual", que foram ações complementares às manifestações na rua, como alternativa para aquelas pessoas que vivem em cidades em que não houve Marcha ou para quem não pode estar presente nos locais públicos.

Com a análise de conteúdo dos posts e comentários dessa categoria, pôde-se constatar que foram frequentes as postagens que buscavam atrair a atenção da sociedade por meio da cobertura dos veículos de comunicação comerciais e da associação da imagem de personalidades midiáticas (atores, apresentadores e jornalistas reconhecidos nacionalmente) para gerar visibilidade à questão defendida pelo grupo mobilizado. Não foi possível constatar, nos textos, o mesmo interesse em acionar veículos ligados a movimentos sociais. Com base nisso, pôde-se inferir que os mobilizadores da ação coletiva visavam à transmissão de suas inquietações ao público diversificado das mídias de maior abrangência e a pessoas que já tinham algum interesse prévio pelo tema.

A intenção de esclarecer ou levar informação qualificada, que muitas mulheres repetem nas postagens, faz com que elas se coloquem em posição de detentoras de informações relevantes e/ou de experiências que precisam ser compartilhadas. Assim,

\footnotetext{
"As ações em torno de uma causa deflagradas por diferentes pessoas ao mesmo tempo ganham nomes diferentes em cada uma das plataformas tecnológicas usadas. No Twitter, por exemplo, a ação de várias pessoas publicarem textos sobre um mesmo tema em um mesmo período de tempo, convencionou-se chamar de "twitaço". O mesmo acontece quando vários autores de diferentes blogs publicam textos sobre um mesmo tema em um mesmo período de tempo (blogagem coletiva). Outras plataformas como a Petição Pública e a Avaaz se propõem a mobilizar os internautas em torno de temas que eles consideram relevantes, fazendo que elas manifestem seu apoio virtualmente, visando dar visibilidade a esses assuntos na mídia, levá-los a pauta de representantes do poder público ou mesmo de organizações internacionais.
} 
seus interlocutores podem ter sido considerados (por elas) pessoas que ainda não tiveram a oportunidade de acessar informações recentes, qualificadas, e refletir de forma mais apurada sobre as problemáticas relacionadas ao parto, ou seja, seriam pessoas que precisariam receber informação. Essa postura pode ser situada em uma lógica da comunicação linear - na qual o processo comunicacional é visto como a transmissão de uma mensagem de um emissor a um receptor, sem considerar as interações e o senso crítico de todos os participantes do processo.

As integrantes da ação coletiva se apropriaram dos recursos tecnológicos para a mobilização, o que possibilitou a abrangência nacional e a instantaneidade; e também conquistou visibilidade acionando formas de protesto tradicionalmente usadas pelos movimentos sociais: protestos de rua, panfletagem, acionamento da mídia, apropriação de técnicas profissionais de comunicação. Como defende Melucci (1996), o discurso e a linguagem têm papel relevante na construção das ações coletivas, uma vez que em seu ponto de vista as mudanças sociais passam pela mudança cultural e pela transformação das relações pessoais. Também foi possível perceber que as integrantes da ação coletiva usaram a linguagem para buscar a transformação da realidade, e que, para isso, criaram expressões que foram usadas em faixas, cartazes e gritos de protesto.

Um exemplo é a busca pela ressignificação da palavra parto, que, no Brasil, é recorrentemente usada de maneira pejorativa, integrando, inclusive, expressões de baixo calão. Quando algumas pessoas questionaram o uso da expressão parto em casa, como tema da manifestação, fizeram-no por recearem que a ação tivesse caráter extremista e não conquistasse a simpatia de muitas pessoas. A preocupação pode ser entendida como uma forma de deixar evidentes os principais objetivos da ação coletiva (defender o direito de escolha das mulheres em relação ao parto e o acesso ao atendimento humanizado), propagando um ponto de vista, sem entrar em embates polêmicos.

\section{Algumas Considerações finais}

É possível concluir que o principal objetivo das ativistas - sensibilizar mais muIheres em relação à problemática relacionada à assistência ao parto - foi atingido por meio das ações de comunicação e de mobilização. E que essa mobilização só foi possível devido a um conjunto de fatores que inclui: a existência de uma rede de pessoas que praticam, promovem e defendem a humanização do parto em diferentes cidades e regiões do país; a mudança de cenário - a partir da exibição da reportagem no Fantástico, o Cremerj se tornou o opositor comum; e o acesso à internet, especialmente o uso do site de rede social Facebook, que possibilitou, em menos de um dia, a replicação da mobilização em diferentes cidades brasileiras. Assim, as ações de comunicação que levaram o tema parto a ser abordado pelos veículos de mídia de massa e a ter sua presença na rede mundial de computadores podem ter contribuído para ampliar a discutibilidade do tema, ou seja, o assunto foi discutido sob o olhar público, caracterizando-se como um exercício democrático (Gomes, 2007).

O caminho da mudança apontado pela ação coletiva analisada é a mudança cultural e comportamental das mulheres para que estas busquem transformar as formas de 
assistência ao parto e, consequentemente, as formas de parir. Mas, para que uma mudança expressiva no sistema ocorra, seria necessário ampliar esse debate para a grande parcela das mulheres brasileiras que são atendidas pelo Sistema Único de Saúde (SUS). A forma como isso venha a ocorrer pode ser a mesma que levou a maioria das ativistas pelo parto humanizado a se envolverem com a causa: a busca de informações pela internet ou a integração a grupos presenciais de apoio, o que pode apontar para a reestruturação do saber sobre o parto, que, em outros períodos históricos, já foi próprio das mulheres e, de certa maneira, foi-lhes roubado. Essas características se aproximam da descrição que Pleyers (2009) faz dos movimentos que buscam maneiras de promover mudanças que não dependem da interlocução direta com as instâncias políticas formais. Na causa do parto humanizado a perspectiva de mudança tem como um dos componentes a transformação da atitude das mulheres, pelo caminho da subjetividade, o que significa a busca pelo respeito às necessidades individuais, às convicções de cada mulher para que seja garantido o seu direito à escolha.

\section{REFERÊNCIAS}

Bardin, L. (2011). Análise de conteúdo. Tradução de Luís Antero Reto e Augusto Pinheiro. São Paulo: Edições 70 .

Castells, M. (Ed.) (2006). A era da informação: economia, sociedade e cultura. A sociedade em rede. v. 1. São Paulo: Paz e Terra.

Castells, M. (Ed.) (2002). A era da informação: economia, sociedade e cultura. O poder da identidade. São Paulo: Paz e Terra.

Cervi, E. U \& Barretta, L. M. (2014). Contra-agendamento na Folha de S.Paulo: opinião pública e presença dos candidatos a presidente do PSDB e PT no jornal (2006 e 2010). Revista Eptic Online, 16 (1), 135-151. Acedido em http://www.seer.ufs.br/index.php/eptic/article/viewFile/1866/1637.

Davis-Floyd, R. (Ed.) (2003). Birth as an American rite of passage. Berkeley: University of California Press.

Felice, M. (2012, jan/abr). Netativismo: novos aspectos da opinião pública em contextos digitais. Revista Fameco Mídia, Cultura e Tecnologia, 19 (1), 27-45.

Gomes, W. (2007, junho). Publicidade, visibilidade, discutibilidade: para uma revisão do conceito de esfera pública política. Comunicação apresentada no Encontro Anual da Compós, Curitiba.

Gamson, W. (2011). Falando de política. Belo Horizonte: Autêntica.

Gonçalves, A. (2014). Da internet às ruas: a marcha do parto em casa. Dissertação de Mestrado, Universidade Federal do Paraná, Curitiba, Brasil. Acedido em http://hdl.handle.net/1884/36284.

Guerra, G. (2008, junho). Violencia obstétrica. RFM. Caracas, Venezuela. Acedido em http://www.scielo.org. ve/scielo.php?script=sci_arttext\&pid=S0798-04692008000100001\&lng=es\&nrm=iso

IHU. Instituto Humanitas Unisinos. (2012, junho). Parto: a cultura médica ainda é muito intervencionista. Entrevista especial com Ana Cristina Duarte. Acedido em http://www.ihu.unisinos.br/ entrevistas/51069o-parto-a-cultura-medica-ainda-e-muito-intervencionista-entrevista-especial-com-anacristina-duarte. 
Luke, S.; Cerdá, J.; Sánchez, M. (2013). O movimento 15M. Ações colectivas e voláteis no campo político. Comunicação e Sociedade, 23, 56-68.

Maia, R. (2011). Prefácio à Edição Brasileira. In W. Gamson, Falando de Política (pp. 17-19), Belo Horizonte: Autêntica.

Melucci, A. (1988). Getting involved: identity and mobilization in social movements. International Social Movement Research, 1, 329-348.

Melucci, A. (1989). Um objetivo para os movimentos sociais?. Lua Nova: Revista de Cultura e Política, (17), 49-66.

Melucci, A. (1996). Challenging codes: collective action in the information age. Cambridge: Cambridge University Press.

Melucci, A. (2001). A invenção do presente. Rio de Janeiro: Vozes.

Pleyers, G. (2009). Autonomias locales y subjetividades em contra del neolideraliso hacia um novo paradigma para entender los movimentos sociales. In Mestries, F., Pleyers, G., \& Zermeño, S., Los Movimientos Sociales: De lo Local a lo Global (pp. 29-156). Barcelona: Anthropos.

Scaggiante, V.; Shub, S. (2012, 21 de fevereiro) Parto Sabrina, Nascimento Lucas - Sabrina Homebirth, Lucas' Birth. Acedido em http://www.youtube.com/watch?v=qiof5vYkPws.

Shirky, C. (2012). Lá vem todo mundo: o poder de organizar sem organizações. Rio de Janeiro: Zahar.

Silverstone, R. (Ed.) (2012). Por que estudar a mídia? São Paulo: Loyola.

Touraine, A. (Ed.) (2007). O mundo das mulheres. Petrópolis: Vozes.

Touraine, A. (Ed.) (2011) Um novo paradigma. Petrópolis: Vozes.

Tornquist, C. S. (2004). Parto e poder: o movimento pela humanização do parto no Brasil. 2004. Tese de Doutorado, Universidade Federal de Santa Catarina, Florianópolis, Brasil. Acedido em http:// repositorio.ufsc.br/xmlui/handle/123456789/86639

Wolton, D. (2003). Internet e depois? Uma teoria crítica das novas mídias. Porto Alegre: Sulina.

Wolton, D. (2004). Pensar a comunicação. Brasília: Universidade de Brasília.

Wolton, D. (2011). Informar não é comunicar. Porto Alegre: Sulinas.

\section{ENTREVISTAS}

Scaggiante, V. (2014, janeiro). Entrevista concedida à autora. Curitiba/Florianópolis.

Leal, G. (2013, novembro). Entrevista concedida à autora via Skype. Curitiba/Sorocaba.

Lotfi, I. (2013, outubro). Entrevista concedida à autora presencialmente. Rio de Janeiro.

Duarte, A. (2013, dezembro). Entrevista concedida à autora via Skype. Curitiba/São Paulo.

Carvalho, P. (2013, novembro). Entrevista concedida à autora via Skype. Curitiba/Recife.

Carvalho, T. (2014, janeiro). Entrevista concedida à autora via Skype. Curitiba/Belém. 
Cavalcante, E. (2014, janeiro). Entrevista concedida à autora via correio eletrônico. Curitiba/Brasília.

Ferigato, S. (2014, julho). Entrevista concedida à autora via e-mail. Curitiba/Campinas.

Monson, I. (2014, janeiro). Entrevista concedida à autora via Skype. Curitiba/Curitiba.

Aline de Oliveira Gonçalves, mestre em comunicação pelo Programa de pós-graduação em comunicação social da Universidade Federal do Paraná (PPGCOM- UFPR), é graduada em comunicação social, com especialização em sociologia política. Atua como jornalista na UFPR. Currículo vitae: http://lattes.cnpq.br/7026341552659511.

E-mail: alinegoncalves@gmail.com

Universidade Federal do Paraná Rua XV de Novembro, 1299 - Centro, Curitiba - PR, 80060-000, Brasil

Celsi Brönstrup Silvestrin, doutora em ciências da comunicação pela USP e mestre em metodologia da comunicação pelo Instituto Metodista de Ensino Superior. Participa dos Grupos de Pesquisa (CNPq): Estudos sobre comunicação organizacional: estratégias e Processos e comunicação e mobilização política. Participou do Núcleo de estudos de gênero da UFPR. É professora senior no PPGCOM-UFPR - linha de pesquisa Comunicação, política e atores coletivos. Currículo vitae: http://lattes.cnpq.br/4860427689856872

E-mail: celsibs@gmail.com

Universidade Federal do Paraná Rua XV de Novembro, 1299 - Centro, Curitiba - PR, 80060-000, Brasil

* Submetido: 16-02-2015

* Aceite: 20-04-2015 